\title{
Woody Encroachment Affects Multiple Dimensions of Ant Diversity in a Neotropical Savanna
}

\section{Karen Neves ( $\nabla$ neves.karen.f@gmail.com )}

Universidade Federal de Uberlandia https://orcid.org/0000-0002-4756-7755

\section{Bernardo Santos}

Museum National d'Histoire Naturelle

\section{Ted Schultz}

Smithsonian Institution

\section{Dietrich Gotzek}

Smithsonian Institution

\section{Rodolfo C.R. Abreu}

Universidade Federal Rural do Rio de Janeiro Instituto de Florestas

\section{Giselda Durigan}

Instituto Florestal

Heraldo L. Vasconcelos

Universidade Federal de Uberlandia

\section{Research Article}

Keywords: alternative stable states, cerrado, fire management, savanna-forest transition, multiplediversity metrics.

Posted Date: December 29th, 2021

DOI: https://doi.org/10.21203/rs.3.rs-1103978/v1

License: (c) (i) This work is licensed under a Creative Commons Attribution 4.0 International License.

Read Full License 
Woody encroachment affects multiple dimensions of ant diversity in a Neotropical savanna

Neves, K. ${ }^{1 *}$, Santos, B. ${ }^{2}$, Schultz, T. ${ }^{3}$, Gotzek, D. ${ }^{3}$, Abreu, R.C.R. ${ }^{4,5}$, Durigan, G. ${ }^{6}$, Vasconcelos, H.L ${ }^{1}$.

${ }^{1}$ Instituto de Biologia, Universidade Federal Uberlândia (UFU), Av. Pará 1720, 38405-320, Uberlândia, Minas Gerais, Brazil

${ }^{2}$ Institut de Systématique, Evolution, Biodiversité (ISYEB), Muséum national d'Histoire naturelle, CNRS, SU, EPHE, UA, 57 rue Cuvier CP50, 75231, Paris Cedex 05, France

${ }^{3}$ Entomology Department, National Museum of Natural History, Smithsonian Institution, 1000

Madison Drive NW, 20560, Washington, District of Columbia, United States of America

${ }^{4}$ Departamento de Ciências Ambientais (DCA), Instituto de Florestas (IF), Universidade Federal Rural do Rio de Janeiro (UFRRJ), Rod. BR 465, Km 07, Seropédica, 23890-000, Rio de Janeiro, Brazil

${ }^{5}$ Department of Plant and Microbial Biology, North Carolina State University (NCSU), Raleigh, NC, United States

${ }^{6}$ Floresta Estadual de Assis, Instituto de Pesquisas Ambientais, Estrada Assis - Lutécia, km 09, Caixa Postal 104, 19802-300, Assis, São Paulo, Brazil

*Corresponding author: neves.karen.f@gmail.com

Author contribution: HLV and KN conceived the ideas; GB, RCRA and HLV designed methodology; RCRA obtained the LAI data; KN, BS, TS and DG obtained the UCE sequence data; KN and HLV collected, analyzed the data and led the writing of the manuscript. All authors contributed critically to the drafts and gave final approval for publication. 


\section{Abstract}

2 Although savanna woody encroachment has become a global phenomenon, few studies have

3 simultaneously evaluated its effects on multiple dimensions and levels of savanna biodiversity.

4 We evaluated how the progressive increase in tree cover in a fire-suppressed savanna landscape

5 affects the taxonomic, functional, and phylogenetic diversity of neotropical ant communities. We

6 sampled ants along an extensive tree cover gradient, ranging from open savannas to forests

7 established in former savanna areas due to fire suppression, and found that Leaf Area Index

8 explained much of the observed variation in ant diversity at both the alpha and beta levels.

9 However, ant responses to variation in tree cover were largely non-linear as differences in alpha

10 diversity and in the dissimilarities of the sampled communities were often much more marked at

11 the savanna/forest transition than at any other part of the gradient. The patterns of functional and

12 phylogenetic diversity mirrored those of taxonomic diversity, notably at the beta level. At the

13 alpha level, functional diversity tended to increase, whereas taxonomic and phylogenetic

14 diversity decreased or was unrelated to tree cover. Our results indicate that savanna ant

15 communities switch rapidly to an alternative state once savanna turns into forest. Ant

16 communities in the newly formed forest areas lacked many of the species typical of the open

17 habitats, suggesting that the maintenance of a fire suppression policy, is likely to result in a

18 decrease in ant diversity and in the homogenization of the ant fauna at the landscape level.

20 Keywords: alternative stable states; cerrado; fire management; savanna-forest transition; multiple 21 diversity metrics. 


\section{Introduction}

Tropical savannas are one of the most biodiverse and most threatened terrestrial biomes

24 (Bond and Parr 2010, Murphy et al. 2016). Expansion of agriculture and cattle ranching has

25 rapidly and substantially reduced the extent of tropical savannas in many parts of the world

26 (Strassburg et al. 2017). Changes in fire regimes are also a threat to tropical savannas, but as

27 opposed to tropical forests, this threat comes not only from frequent, severe and/or uncontrolled

28 fires, but also from fire suppression (Bond and Parr 2010, Rosan et al. 2019). Fire was a key

29 element in the evolution of tropical savannas and as such many species of its flora have

30 adaptations to or are dependent on fire (Simon and Pennington 2012). In the absence of fire, the

31 tree cover gradually increases and, as a result, savannas can be replaced by forests, notably in

32 high-resource environments (Hoffmann et al. 2012) or in transitional regions where forest

33 remnants share the landscape with grassland and savanna patches. In higher-rainfall savannas

34 (also known as mesic savannas), for instance, this process can take place within a matter of only

35 a few decades (Abreu et al. 2017, Durigan 2020). The biome shift from savanna to forest

36 involves a major switch in the structure and composition of plant communities - with the

37 replacement of fire-adapted species by species that are both fire-sensitive and shade-tolerant -,

38 so that forests and savannas are regarded as alternative stable states mediated by plant-fire

39 feedbacks (Hoffmann et al. 2012; Dantas et al. 2013).

While the patterns and mechanisms involved in the development of the vegetation in fire-

41 suppressed savanna areas are relatively well documented (e.g., Stevens et al. 2017, Flake et al.

42 2021), relatively little is known about how animal communities respond to woody encroachment

43 (but see Woinarski et al. 2008, Leitner et al. 2018). The few existing studies have compared

44 communities from areas with highly contrasting woody-plant cover (such as those that have been 
45 protected from fire for a relatively long time versus those that have been burned, e.g., Andersen

46 et al. 2006) and therefore it is unclear whether the observed changes in the structure of animal

47 communities are gradual or rather become more abrupt at certain phases of the woody

48 encroachment process.

49 Furthermore, there is limited information on the extent to which woody encroachment

50 affects the functional and phylogenetic structure of savanna communities (but see Parr et al.

51 2012). Measures of functional and phylogenetic diversity can complement those provided by the

52 traditional taxonomic diversity metrics given that they take into account the evolutionary history

53 and the functional traits of the members of a community. Functional diversity is a key

54 component of biodiversity as it provides a link between species traits (morphological,

55 physiological, or behavioral) and the role they play in the environment (Swenson 2014).

56 Phylogenetic diversity, in turn, helps to address whether species in a community are drawn from

57 the same clades or from distantly related lineages (Webb et al 2002, Cavender-Bares et al 2006).

Herein we combine species occurrence data drawn from extensive fieldwork, a species-

59 level phylogeny built with phylogenomic data, and functional metrics drawn from a

60 morphological dataset to evaluate the extent to which variation in tree cover in a fire-suppressed

61 savanna landscape affects the taxonomic, functional, and phylogenetic diversity of Neotropical

62 ant communities at the alpha and beta levels. More specifically, we tested the hypothesis that

63 habitat openness is key driver of variation in ant communities (Andersen, 2019). For this, we

64 sampled ants along an extensive tree cover gradient, ranging from open savannas to recently

65 formed forest areas, and asked the following questions: (a) What is the relationship between tree

66 cover and ant diversity? (b) Are changes in ant diversity along the tree cover gradient gradual or

67 is there evidence of a rapid switch from one community state to another at a particular point of 
68 the gradient? (c) To what extent are responses of phylogenetic and functional diversity congruent 69 with those of taxonomic diversity?

\section{$71 \quad$ Material and Methods}

\section{Study area}

73 The study was performed at Santa Barbara Ecological Station (SBES), a biological

74 reserve with an area of 2,715 ha located in Águas de Santa Barbara, São Paulo, Brazil (2248'S,

$7549^{\circ} 14^{\prime} \mathrm{W}$ ), at an elevation 600 to $680 \mathrm{~m}$ a.s.l. Climate in the region is classified as Koppen's

76 Cwa, characterized by a warm summer and a dry winter (Alvares et al. 2013), annual rainfall

77 varies from 1,000 to $1,300 \mathrm{~mm}$, and mean temperature of the coldest month is $18^{\circ} \mathrm{C}$, while the

78 hottest month exceeds $22^{\circ} \mathrm{C}$ of temperature (Meira-Neto et al. 2007).

79 At SBES, a fire suppression policy was in force for several decades, and an analysis of

80 the vegetation development over a 30-yr period (1985-2015) shows a steady temporal increase

81 in tree cover (Abreu et al. 2017). At the time of our study, several of the former grassland and

82 open savanna areas had turned into dense savanna or even forest (Abreu et al. 2017). In 2015, a

83 prescribed fire experiment was initiated at SBES (Durigan et al. 2020) and the data analyzed here

84 represents pre-fire data collected in December 2014 in all plots (each $20 \times 50 \mathrm{~m}$ ) designated for

85 the fire experiment. These plots encompassed the entire variation in tree cover found in the study

86 area and included plots established in open savanna (campo sujo), dense savanna (cerrado sensu

87 stricto), and forest (cerradão). The fire history differs slightly among the study plots: 23 of the

8830 plots did not burn over the 1985-2015 period, six burned once, and one several times. The last

89 fire event in any plot took place in 2011. 
As a measure of tree cover in each plot at the time of our sampling, we used the Leaf

93 Area Index (LAI), a satellite-derived metric that is strongly and positively correlated with tree

94 basal area (Abreu et al. 2017). LAI data for the study plots was obtained in April and May 2015.

95 Each sampling plot was subdivided into ten subplots of $10 \times 10 \mathrm{~m}$. Each subplot had four

96 collection points of LAI with hemispherical photographs. Photos were taken before sunrise, after

97 sunset, or under homogeneous overcast skies. A tripod was used to position the camera (Canon

98 EF 8-15mm fisheye lens) at a height of $1 \mathrm{~m}$, and the top of the camera was oriented relative to the

99 north. Photos were taken with un underexposure of on f stop (Macfarlane et al. 2014), and the

100 color images we converted to black and white using Hemisfer 2.12 (Thimonier et al. 2010;

101 Schleppi et al. 2007) and using maximum blue contrast (Nobis and Hunziker 2005). The images

102 were then analyzed with Hemisfer 2.12 using an automatic threshold for closed-canopy

103 vegetation and with a supervised manual threshold under open canopies. The LAI values were

104 averaged over the 40 subplots to obtain a single value for each plot (for more details see Abreu et 105 al. 2017).

106

107 Ant sampling

108 We used pitfall traps as the only method to sample ants as the large number of traps 109 installed (600 in total) and the amazing abundance and diversity of ants at SBES precluded the 110 use of other sampling methods. A total of 20 pitfall traps were installed in each plot, arranged in 111 five grids of approximately $2.5 \times 2.5 \mathrm{~m}$ (keeping a minimum distance of $20 \mathrm{~m}$ between any two 112 grids), with four pitfall traps installed at the corners of each grid. Each trap consisted of a small 113 plastic cup $(250 \mathrm{ml}, 8.5 \mathrm{~cm}$ high and $7.8 \mathrm{~cm}$ in diameter) partially filled with water and 
114 detergent. The traps remained in operation for 48 hours. Upon collection, the contents from the

115 four traps set within the same grid were combined to make a composite sample. In the lab, ant

116 workers were sorted into morphospecies and a representative specimen from each sample was

117 dry-mounted for subsequent identification using available taxonomic keys (Fernández 2003,

118 Bolton et al. 2007, Fernádez and Ortiz-Sepúlveda 2019) or by comparison with specimens

119 previously identified by ant taxonomists deposited at the Zoological Collection of the Federal

120 University of Uberlândia (UFU), where the specimens collected were also deposited. Specimens

121 for which a species-level identification was not possible received a morphospecies code.

122

123 Ant phylogeny

124 To compute the phylogeny-based diversity metrics (as detailed below), we used a

125 maximum-likelihood tree created using DNA sequences of ultraconserved elements (UCEs) for

126 one representative specimen of 167 of the 180 species/morphospecies collected (Online

127 Resource 1: Fig. 1). Laboratory methods for sequence generation followed well-established

128 protocols for library preparation, targeted capture, and sequencing of UCE data (see Online

129 Resource 2 for a detailed overview). For the enrichment of UCE loci, we used an ant-customized

130 bait set ("myBaits UCE Hymenoptera 2.5Kv2A"; ArborBiosciences, MI) that includes 9,898

131 baits targeting 2,524 UCE loci conserved in Hymenoptera (Branstetter et al. 2017).

132 All sequence data processing and analysis was conducted using the Smithsonian's High-

133 Performance Computing cluster (Smithsonian Institution 2021). Sequencing reads were filtered

134 and trimmed using Illumiprocessor (Faircloth 2013) and assembled using Trinity v. r2013-02-25

135 (Grabherr et al. 2011). The resulting contigs were then processed following the Phyluce v1.5

136 pipeline (Faircloth 2016). The UCE loci were extracted to separate FASTA files, and each locus 
137 was aligned using MAFFT v. 7.130b (Katoh et al. 2002) and trimmed with GBLOCKS v. 0.91b

138 (Castresana 2000). The alignment was filtered to include only loci available for at least 50\% of

139 the taxa, resulting in alignment including 2,258 loci. The concatenated dataset was partitioned by

140 partition schemes defined by PartitionFinder2 (Lanfear et al. 2016), incorporating also the

141 SWSC-EN algorithm (Tagliacollo and Lanfear 2018). The maximum-likelihood analyses were

142 run with IQTREE v. 1.6.12 (Nguyen et al. 2015).

143

144 Ant morphological data and phylogenetic signal

145 We measured five morphological traits that are commonly used in studies of ant

146 functional diversity (Weiser and Kaspari 2006, Parr et al. 2017; Martello et al 2018; Online

147 Resource 1: Table 2). Measurements were made of at least five specimens from each species;

148 when fewer than five specimens were available, we measured all specimens. Whenever possible,

149 the measured individuals were from different sampling plots. A detailed account of the

150 hypothesized functions of each trait can be found in Parr et al. (2017) and Martello et al. (2018)

151 but, briefly, (1) Weber's length is a measure of body size and is correlated with metabolic

152 characteristics; (2) eye length is indicative of food searching behavior; (3) inter-ocular distance is

153 involved in the perception of habitat complexity and the performance of visual predators; (4)

154 femur length is indicative of locomotory abilities and food searching behavior; (5) mandible

155 length is indicative of the ant's diet (Table S2). Prior to the analyses we obtained a relative

156 measure of each trait (except Weber's length) by dividing the value of the particular trait by the

157 Weber's length of the measured ant individual. All trait measures were then standardized to zero

158 mean and unit variance. 
We evaluated the degree of phylogenetic signal for each measured morphological trait

160 using the Blomberg's K statistic (Blomberg et al. 2003). This metric uses a Brownian motion of

161 trait evolution to evaluate whether the observed distribution of trait values differs from

162 expectation under Brownian motion. K-values close to 1 indicate that traits exhibit phylogenetic

163 signal, indicating that closely related species have more similar traits than expected under the

164 Brownian motion model; K-values close to 0 indicate an absence of phylogenetic signal,

165 meaning that closely related species are not more similar in their traits than distantly related

166 species (Blomberg et al. 2003). The statistical significance of observed K-values was assessed

167 through randomization tests that produced a null distribution of $999 \mathrm{~K}$-values. We used the R

168 package "phytools" (Revell 2012) to compute phylogenetic signals and statistical significance.

\section{Diversity metrics}

171 A dataset was built using information about the number of occurrences of each species in

172 each plot (number of grids in which the species was recorded, for a maximum of five grids in

173 each plot), the functional traits of each species, and the phylogenetic relationship between

174 species. To estimate the taxonomic, functional, and phylogenetic alpha diversity of ant

175 communities in each plot and the dissimilarity (beta diversity) between communities in different

176 plots, we used the Rao's quadratic entropy index (Rao 1982, Pavoine et al. 2005). The Rao index

177 is known to reflect community assembly processes well (Mouchet et al. 2010) and allows

178 comparing the alpha and beta components of taxonomic, functional, and phylogenetic diversity

179 within the same mathematical framework (De Bello et al. 2010). All diversity metrics were

180 calculated using the "Rao" function and applying Jost's correction as recommended by De Bello

181 et al. (2010). We estimated the pairwise functional and phylogenetic Euclidean distances 
182 between species using the functions "daisy" and "cophenetic.dist". The functions are

183 implemented by "cluster" and "picante" packages, respectively (Maechler et al. 2019, Paradis

184 and Schliep 2018).

185 The standardized effect size (SES) of the functional and phylogenetic, alpha and beta

186 diversity metrics were also calculated. Standardized metrics are less sensitive to species richness

187 differences and, in addition, allow the test of hypotheses regarding the functional and

188 phylogenetic structure of the communities (Webb 2000). Negative values of SES $(<-1.96)$ are

189 indicative of a clumped structure (i.e., greater importance of environmental filtering in

190 determining the traits or lineages that are found in a given community), whereas positive values

191 ( $>1.96)$ are indicative of a dispersed, functional or phylogenetic structure (i.e., greater

192 importance of interspecific competition and niche partitioning) (Gotelli and Rohde 2002). We

193 generated null communities by randomizing (999 randomizations) the community data matrix

194 using the 'independent swap' algorithm. This algorithm maintains the row and column totals of

195 the original matrix, meaning that the species richness and total number of ant records in each plot

196 are not altered (Gotelli 2000). The null models were built using the "picante" package (Kembel

197 et al. 2010). Then, we determined the difference between the observed diversity value and the

198 mean of the null values and divided this difference by the standard deviation of the null values.

199 All analyses were performed using the R environment (R Core Team 2021).

\section{Statistical analyses}

202 We evaluated the relationship between tree cover and alpha diversity (taxonomic,

203 functional or phylogenetic) using both linear and non-linear (quadratic and generalized additive - 
204 GAM) regression models and selected the most appropriated model using the Akaike 205 Information Criterion.

206 We performed Multiple Regression on Distance Matrices (MRDM) to assess the 207 influence of geographic distance and tree cover on the taxonomic, functional, or phylogenetic 208 dissimilarities between ant communities from different plots. The MRDM was based on 209 Spearman correlation between the distance (dissimilarity) matrices, in order to test for a 210 monotonic but not necessarily linear relationship between the matrices (Goslee and Urban 2007).

211 We used the Euclidean distance to build the matrix of dissimilarity in tree cover (using the LAI 212 of each plot) and the geographic distance matrix (using the coordinates of each plot). Statistical

213 significance of the predictor variables was assessed through permutation tests (1000

214 permutations). To assess the unique and shared influences of geographic distance and

215 dissimilarity in tree cover on the dissimilarity (taxonomic, functional, or phylogenetic) of the 216 sampled communities we partitioned the total variance explained by each model into percentages 217 explained by each predictor variable alone or in combination (Borcard et al. 1992).

218 To illustrate differences in taxonomic, functional, or phylogenetic composition of the 219 sampled communities, we built non-metric multidimensional (nMDS) ordination plots based on 220 the matrices of pairwise dissimilarities generated by the "Rao" function. We evaluated if 221 communities in plots classified as forest (i.e., with a LAI > 2, cf. Abreu et al. 2017) at the time of 222 our study differed from those in dense $(\mathrm{LAI}<2$ and $>0.5)$ or open savanna (LAI $<0.5$; Fig. 1d) 223 using a Multivariate Analysis of Variance (MANOVA) and the ordination scores generated by 224 our two-dimensional ordination analysis as the response variable (Peck 2011).

225 Moran's I correlogram (Dray et al. 2011), based on six distance classes, were built to 226 assess the presence of spatial autocorrelation in model residuals (Online Resource 1: Fig. 2). 
227 Analyses were performed in R version 3.6.1 using the 'vegan', 'ecodist', and 'mgev' packages

228 (R core team 2021, Oksanen et al. 2020, Goslee and Urban 2007, Wood 2017).

230 Results

231 In total, we had 2,158 specimen records of 180 ant species from 51 genera (Online

232 Resource 1: Table 1) The most diverse genus was Pheidole with 35 species, followed by

233 Camponotus (16 species) and Solenopsis (9 species). The most common ant species were

234 Pheidole oxyops, Pheidole fracticeps, Solenopsis sp. 01, Ectatomma permagnum and

235 Pachycondyla striata. Together they accounted for $20.01 \%$ of all ant specimen records.

236 All five morphological traits exhibited Blomberg's K values of less than one, indicating a

237 significant albeit weak phylogenetic signal (Online Resource 1: Table 2).

239 Tree cover and alpha diversity

240 We found significant variation in the taxonomic, functional, and phylogenetic alpha

241 diversity of ant communities along the tree cover gradient (Fig. 1, Online Resource 1: Table 3).

242 Taxonomic alpha diversity (TD) presented a non-linear relationship with LAI, peaking at LAI

243 values around one and showing a more abrupt decline at values $>2$ (Fig. 1a). Phylogenetic alpha

244 diversity (PD) was strongly correlated with TD $(r=0.814, \mathrm{p}<0.001)$ and, accordingly, showed a

245 negative relationship with LAI (Fig. 1e). However, this relationship was no longer significant

246 when we controlled for the effect of taxonomic diversity using a null model approach (ses.PD;

247 Fig. 1f; Online Resource 1:Table 3). Looking at all the 30 ant communities sampled along the

248 tree cover gradient we found that mean ses.PD did not differ significantly from zero (one sample

$249 \mathrm{t}$-test, $\mathrm{t}=1.20, \mathrm{p}=0.12$ ). 
Functional alpha diversity (FD) was not correlated to either TD $(r=-0.265, \mathrm{p}=0.14)$ or

$251 \mathrm{PD}(\mathrm{r}=-0.115, \mathrm{p}=0.53)$. Both FD and ses.FD showed a positive, non-linear relationship with

252 LAI (Fig. 1b and c). There was a trend toward more positive than negative ses.FD values,

253 notably in plots with a greater tree cover (LAI > 2; Fig. 1c), but the mean ses.FD was not

254 significantly different from zero (one sample $\mathrm{t}$-test, $\mathrm{t}=1.58, \mathrm{p}=0.063$ ).

255 Overall, we did not detect any sign of spatial autocorrelation in the residuals of the 256 models that evaluated the influence of LAI on ant alpha diversity (Online Resource 1: Fig. 2).

\section{Tree cover and beta diversity}

Our multiple regression analyses indicate that geographic distance accounted for only a

260 small and nearly negligible part of the observed dissimilarities in the taxonomic composition of

261 the ant communities. Rather, much of the observed dissimilarity in the taxonomic composition of

262 the sampled communities was explained by the dissimilarity in tree cover (LAI) among the 263 survey plots (Fig. 2, Online Resource 1: Fig. 3).

264 The ordination analyses reinforced the view that variation in tree cover is a strong

265 determinant of variation in taxonomic beta diversity. Notably, we found strong differences in the

266 taxonomic composition between ant communities in plots with a LAI greater or lower than 2;

267 i.e., between the forest and the dense or open savanna plots (Manova, followed by Hotelling's T-

268 squared all-pairs comparison, p <0.001; Fig. 3). Species such as Acromyrmex subterraneus,

269 Carebara brevipilosa, Gnamptogenys striata, Hypoponera sp. 14, Neoponera marginata,

270 Nylanderia sp. 05, and Pheidole fimbriata were found only or mostly in the forest plots, whereas

271 species such as Apterostigma sp. 01, Camponotus renggeri, Cephalotes pusillus, Dinoponera

272 australis, Dorymyrmex goeldii, Ectatomma opaciventris, Linepithema cerradenses, 
273 Mycetophylax lectus, Pheidole jelskii and Solenopsis loretana only or predominantly in the

274 savanna plots (Online Resource 1: Fig. 4). Only a few species, such as Forelius albiventris,

275 Gnamptogenys sp. 05, Pogonomyrmex naegelli and Pheidole schwarzmaieri, were more

276 characteristic of the most open savanna plots (LAI < 0.5; Online Resource 1: Fig. 4)

277 Patterns of functional and phylogenetic beta diversity were correlated with those of

278 taxonomic beta diversity (standardized Mantel statistic: $\mathrm{FD}=0.653$; ses.FD $=0.649 ; \mathrm{PD}=0.762$

279 ; ses.PD $=0.693, \mathrm{P}<0.001$ in all Mantel tests with TD). Therefore, as also found for taxonomic

280 beta diversity, both the functional and phylogenetic dissimilarities of the sampled communities

281 increased as the dissimilarity in tree cover increased (Online Resource 1: Fig. 3), even though the

282 standardized effect size of these metrics indicate that in general beta FD and PD values were not

283 different from random expectation (Online Resource 1: Fig. 3).

284 Differences in the functional and phylogenetic composition of ant communities were

285 particularly marked between the forest and savanna plots, with differences in ordination scores

286 between these two groups being significant in all the analyses (Manova, followed by Hotelling's

287 T-squared all-pairs comparison, $\mathrm{p}<0.025$ in all pairwise comparisons, Fig. 3). Differences

288 between open and dense savanna plots were only significant in the analyses of phylogenetic

289 composition (PD Hotelling's T-squared $=10.9, \mathrm{p}=0.02$ : ses.PD, Hotelling's T-squared $=14.5, \mathrm{p}$

$290<0.008$, Fig. 3).

292 Discussion

293 Our study is the first to evaluate how variation in tree cover within a savanna-dominated

294 landscape (the Cerrado) affects the taxonomic, functional, and phylogenetic diversity of ground-

295 dwelling ants at the alpha and beta levels. We sampled ants along a relatively large tree cover 
296 gradient and found that variation in tree cover (and thus in habitat openness) explained much of

297 the variation in ant diversity. Furthermore, we found that variation in ant diversity was not

298 uniform along the tree cover gradient. Rather, there is evidence of thresholds, at which major

299 changes occur. At the alpha level, for instance, we found relatively little variation in taxonomic

300 diversity (TD) along the first half of the tree cover gradient (i.e., from open to dense savanna),

301 but at plots that became forest as result of the fire suppression policy at our study site (plots with

302 a LAI > 2), alpha TD declined sharply.

303 In addition, there were marked differences in the taxonomic composition (beta diversity)

304 between the forest and savanna communities, with several species occurring exclusively or

305 predominantly in one side of the gradient, whereas those that were found throughout the tree

306 cover gradient often showed major shifts in abundance at the savanna-forest transition. That

307 woody encroachment resulting from fire suppression can affect the species richness and

308 composition of savanna ant communities has been demonstrated previously (Andersen et al.

309 2006, Maravalhas and Vasconcelos 2014, Abreu et al. 2017). However, as shown here, changes

310 are largely non-linear, with savanna ant communities switching rapidly to an alternative state

311 once savanna turns into forest. In this sense, patterns of taxonomic ant diversity in tropical

312 savannas subject to woody encroachment appear to be in sharp contrast with those found in

313 studies of secondary succession in tropical forests, during which ant diversity changes gradually

314 as the forest grows older (Bihn et al. 2010, Rocha-Ortega et al. 2018).

315 Patterns of functional and phylogenetic beta diversity largely mirrored those of

316 taxonomic beta diversity. The major changes in the functional and phylogenetic composition of

317 ant communities often occurred at the savanna-forest transition, indicating that the observed

318 turnover of species at this transition resulted in concomitant changes in the traits and lineages of 
319 the species composing the local communities. Studies in Australia also report marked turnover of

320 ant species at the savanna/forest transition (Andersen et al. 2012, Andersen 2019), suggesting

321 that the non-linear response of the ant fauna to variation in tree cover that we detected here

322 occurs more widely in tropical savannas.

323 Functional and phylogenetic diversity showed contrasting responses to variations in tree

324 cover at the alpha level, and this may well reflect the fact that all morphological/functional traits

325 we measured showed a weak phylogenetic signal (Cadotte et al. 2013). In general, savanna plots

326 presented greater alpha PD than did the forest plots, indicating that the diversity of ant lineages

327 was greater in the former than in the latter. In contrast, alpha FD tended to increase as the tree

328 cover increased. Nevertheless, the relationship between PD and tree cover (but not that between

329 FD and tree cover) disappeared when the difference in species richness between the sampled

330 communities was taken into account using a null model approach (ses.PD). This indicates that

331 the relationship between PD and tree cover was largely mediated by the variation in TD along

332 the gradient. This was expected given the strong correlation between TD and PD. The correlation

333 between TD and other diversity metrics (FD and PD) has been reported previously. For instance,

334 the dependency of these diversity metrics on TD was detected in studies comparing ant

335 communities in contrasting habitats (Blaimer et al. 2015, Agavekar et al. 2019, Dröse et al. 2019)

336 and along elevational gradients (Silvestre et al. 2021).

337 In none of the ant communities we sampled did we find greater or lower than expected

338 PD (given the TD of the community), suggesting that these communities have a random

339 phylogenetic structure. Similarly, all the communities sampled presented non-significant ses.FD

340 values. However, communities in the more closed habitats tended to present more positive

341 ses.FD values than those in the more open habitats, suggesting that the relative importance of 
342 interspecific competition and niche partitioning in structuring these communities potentially

343 increases as tree cover increases. Studies of tropical forest succession also found significant

344 variation in the FD of ant communities (Bihn et al. 2010, Rocha-Ortega et al. 2018), and there is

345 evidence that such variation appears to be associated with the greater occurrence of

346 morphologically unique, predatory species in the more advanced successional stages (Rocha-

347 Ortega et al. 2018, Santoandré et al. 2019). Similarly, here we found that predatory species of the 348 genera Hypoponera, Odontomachus, and Pachycondyla were largely associated with the more 349 closed forest plots.

\section{Conclusions}

352 Overall, our results give support to the idea that habitat openness is a key driver of 353 variation in ant communities, and that ant responses to disturbance are strongly linked to their 354 responses to habitat openness (Andersen 2019). In addition, we found strong support to the idea 355 that fire mediates alternative states of ant communities in tropical savannas (Andersen et al.

356 2012). Thirty years of a fire suppression policy at our study area resulted in a substantial increase

357 in tree cover, with former grassland and savanna areas becoming forest in several cases (Abreu et 358 al. 2017). Where this occurred, the ant community changed abruptly, as the newly formed forest 359 areas favored the development of a shade-adapted fauna at the expense of the fauna more 360 characteristic of the savanna habitat. Forests and savannas coexist in many tropical landscapes, 361 and such habitat heterogeneity is key to explaining the high local diversity of many taxonomic 362 groups (e.g. da Mata and Tidon 2013, Ribeiro et al. 2020, Costa et al. 2020), including ants 363 (Pacheco and Vasconcelos, 2012). Therefore, the adoption of a fire suppression policy, as is 364 currently the case in many protected areas of the Cerrado, is likely to result in the local loss of 
365 many open habitat specialists, and consequently in a decrease in ant diversity and in the 366 homogenization of the ant fauna at the landscape level. Ecosystem management in such

367 landscapes should aim at maintaining the high heterogeneity of habitats which characterizes the 368 alternative states within the Cerrado biome. 
We thank R. Pacheco and J. Vieira for helping with the ant sorting and taxonomic

371 identification. E. Koch and J. Maravalhas for helping with the field work, W. Hoffman for

372 helping design and set up the fire experiment and collect the LAI data, and A. Andersen for

373 commenting on a previous version of the manuscript. KN was supported by a Peter Buck

374 Predoctoral Fellowship at the Smithsonian Institution's National Museum of Natural History and

375 a PhD scholarship from CAPES. The laboratory and the computer work were conducted in and

376 with the support of the LAB facilities of the National Museum of Natural History and the

377 Smithsonian Institution OCIO team.

\section{Declarations}

$380 \quad$ Funding

381 This study was supported by grants from the Brazilian Council of Research and Scientific

382 Development (CNPq grants 302588/2015-9, 304628/2020-4 to HLV, and 309709/2020-2 to

383 GD), and the U.S. National Science Foundation (NSF grant 1654829 to TRS, DEB-1354943 to

384 W. Hoffmann, and DEB-1654829 and CAREER DEB-1943623 to Christian Rabeling).

\section{Conflicts of interest/Competing interests}

386 The authors declare that they have no conflict of interest.

387 Ethics approval

$388 \quad$ Not applicable

389 Consent to participate

$390 \quad$ Not applicable

391 Consent for publication 
392 Not applicable

393 Availability of data and material

394 After acceptance for publication, the DNA sequence data will be deposited in a proper

395 repository.

396 Code availability

397 Not applicable

398 


\section{Literature Cited}

400 Abreu RCR Hoffmann WA, Vasconcelos HL, Pilon NA, Rossatto DR, Durigan G (2017) The

401 biodiversity cost of carbon sequestration in tropical savanna. Science Advances. 3:e1701284.

402 https://doi.org/10.1126/sciadv.1701284

403

404 Agavekar G, Agashe D, and Economo EP (2019) Dimensions of ant diversity on a small tropical 405 island. Insect Conservation and Diversity. 12:161-171. https://doi.org/10.1111/icad.12326

407 Alvares CA, Stape JL, Sentelhas PC, Gonçalves JLM and Sparovek G (2013) Köppen’s climate 408 classification map for Brazil. Meteorologische Zeitschrisft. 22:711-728.

409 https://doi.org/10.1127/0941-2948/2013/0507

410

411 Andersen AN, Hertog T and Woinarski JC (2006) Long-term fire exclusion and ant community

412 structure in an Australian tropical savanna: congruence with vegetation succession. Journal of

413 Biogeography. 33: 823-832. https://doi.org/10.1111/j.1365-2699.2006.01463.x

414

415 Andersen AN, Woinarski JC, and Parr CL (2012) Savanna burning for biodiversity: fire

416 management for faunal conservation in Australian tropical savannas. Austral Ecology. 37:658-

417 667. https://doi.org/10.1111/j.1442-9993.2011.02334.x

418

419 Andersen AN (2019) Responses of ant communities to disturbance: five principles for

420 understanding the disturbance dynamics of a globally dominant faunal group. Journal of Animal

421 Ecology. 88:350-362. https://doi.org/10.1111/1365-2656.12907 
423 Bihn JH, Gebauer G and Brandl R (2010) Loss of functional diversity of ant assemblages in

424 secondary tropical forests. Ecology. 91: 782-792. https://doi.org/10.1890/08-1276.1

425

426 Blaimer BB, Brady SG, Schultz TR, Fisher BL (2015) Functional and phylogenetic approaches

427 reveal the evolution of diversity in a hyper diverse biota. Ecography 38:901-912.

428 https://doi.org/10.1111/ecog.01370

429

430 Blomberg SP, Garland TJR, and Ives AR (2003) Testing for phylogenetic signal in comparative

431 data behavioral traits are more labile. Evolution. 57: 717-745. https://doi.org/10.1111/j.0014-

$432 \quad 3820.2003 . t b 00285 . x$

433

434 Bolton B, Alpert G, Ward PS, Naskrecki P (2007) Bolton's catalogue of ants of the world.

435 (Harvard University Press, 2007). https://doi.org/10.5860/choice.44-6566

436

437 Bond WJ and Parr CL (2010) Beyond the forest edge: ecology, diversity and conservation of the 438 grassy biomes. Biological Conservation. 143: 2395-2404.

439 https://doi.org/10.1016/j.biocon.2009.12.012

440

441 Borcard D, Legendre P and Drapeau P (1992) Partialling out the spatial component of ecological 442 variation. Ecology. 73:1045-1055. https://doi.org/10.2307/1940179 
444 Branstetter MG, Longino JT, Ward PS and Faircloth BC (2017) Enriching the ant tree of life:

445 enhanced UCE bait set for genome-scale phylogenetics of ants and other Hymenoptera. Methods

446 Ecology and Evolution. 8: 768-776. https://doi.org/10.1111/2041-210X.12742

447

448 Cadotte M, Albert CH and Walker SC (2013) The ecology of differences: assessing community

449 assembly with trait and evolutionary distances. Ecology Letters, 16:1234-1244.

450 https://doi.org/10.1111/ele.12161

451

452 Castresana J (2000) Selection of conserved blocks from multiple alignments for their use in

453 phylogenetic analysis. Molecular Biology and Evolution. 17:540-52.

454 https://doi.org/10.1093/oxfordjournals.molbev.a026334

455

456 Cavender-Bares J, Keen A and Miles B (2006) Phylogenetic structure of Floridian plant

457 communities depends on taxonomic and spatial scale. Ecology. 87:109-122.

458 https://doi.org/10.1890/0012-9658(2006)87[109:PSOFPC]2.0.CO;2

459

460 Costa BM, Pantoja DL, Sousa HC, de Queiroz TA and Colli GR (2020) Long-term, fire-induced

461 changes in habitat structure and microclimate affect Cerrado lizard communities. Biodiversity

462 and conservation. 29:1659-1681. https://doi.org/10.1007/s10531-019-01892-8

463

464 Da Mata RA and Tidon R (2013) The relative roles of habitat heterogeneity and disturbance in

465 drosophilid assemblages (Diptera, Drosophilidae) in the Cerrado. Insect Conservation and

466 Diversity. 6:663-670. https://doi.org/10.1111/icad.12020 
468 Dantas VL, Batalha MA and Pauasas JG (2013) Fire drives functional thresholds on the savanna469 forest transition. Ecology 94: 2454-2463. https://doi.org/10.1890/12-1629.1

471 De Bello F, Lavergne S, Meynard CN, Leps J and Thuiller W (2010) The partitioning of 472 diversity: showing Theseus a way out of the labyrinth. Journal of Vegetation Science 21:992473 1000. https://doi.org/10.1111/j.1654-1103.2010.01195.x

475 Dray, S (2011) A new perspective about Moran's coefficient: spatial autocorrelation as a linear 476 regression problem. Geographical Analysis. 43:127-141. https://doi.org/10.1111/j.1538-

$477 \quad 4632.2011 .00811 . x$

478

479 Dröse W, Podgaiski LR, Dias CF and Mendonça MS (2019) Local and regional drivers of ant 480 communities in forest-grassland ecotones in South Brazil: a taxonomic and phylogenetic 481 approach. Plos one 14:1-20. https://doi.org/10.1371/journal.pone.0215310 482

483 Durigan G (2020) Zero-fire: Not possible nor desirable in the Cerrado of Brazil. Flora. 268:

484 151612. https://doi.org/10.1016/j.flora.2020.151612

485

486 Faircloth BC, MacCormack JE, Crawford NG, Harvey MG, Brumfield RT, Glenn TC (2012)

487 Ultraconserved elements anchor thousands of genetic markers sapanning multiple evolutionary 488 timescales. Systematic Biology. 61:717-726. https://doi.org/10.1093/sysbio/sys004 
490 Faircloth BC (2013) Illumiprocessor: a trimmomatic wrapper for parallel adapter and quality

491 trimming. http://dx.doi.org/10.6079/J9ILL.

492

493 Faircloth BC (2016) PHYLUCE is a software package for the analysis of conserved genomic 494 loci. Bioinformatics. 32: 786-788. https://doi.org/10.1093/bioinformatics/btv646

495

496 Fernández F (2003) Introducción a las hormigas de la región Neotropical. Instituto de

497 Investigación de Recursos Biológicos Alexander von Humboldt, Bogotá.

498

499 Fernández F, Ortiz-Sepúlveda CM (2019). Subfamily Formicidae. In: Fernandez F, Guerrero RJ,

500 Delsinne T. Hormigas de Colombia. Universidad Nacional de Colombia. Bogotá. pp 721-741.

502 Flake SW, Abreu RCR, Durigan G and Hoffmann WA (2021) Savannas are not old fields:

503 Functional trajectories of forest expansion in a fire-suppressed Brazilian savanna are driven by

504 habitat generalists. Functional Ecology. 35:1797-1809. https://doi.org/10.1111/1365-2435.13818

505

506 Goslee SC and Urban DL (2007) The ecodist package for dissimilarity-based analysis of

507 ecological data. Journal of Statistical Software. 22:1-19. https://doi.org/10.18637/jss.v022.i07

508

509 Gotelli NJ (2000) Null model analysis of species co-occurrence patterns. Ecology. 81: 2606-

510 2621. https://doi.org/10.1890/0012-9658(2000)081[2606:NMAOSC]2.0.CO;2 
512 Gotelli NJ and Rohde K (2002) Co-occurrence of ectoparasites of marine fishes: a null model

513 analysis. Ecology Letters. 5:86-94. https://doi.org/10.1046/j.1461-0248.2002.00288.x

515 Grabherr MG, Haas BJ, Yassour M, Levin JZ, Thompson DA, Amit I, Adiconis X, Fan L,

516 Raychowdhury R, Zeng Q, Chen Z, Mauceli E, Hacohen N, Gnirke A, Rhind N, de Palma F,

517 Birren BW, Nusbaum C, Lindblad-Toh K and Friedman N (2011) Trinity: reconstructing a full-

518 length transcriptome without a genome from RNA-Seq data. Nature Biotechnology. 29: 644-652.

519 https://doi.org/10.1038/nbt.1883

520

521 Hoffmann WA, Geiger EL, Gotsch SG, Rossatto DR, Silva LCR, Lau OL, Haridasan M, and

522 Franco AC (2012) Ecological thresholds at the savanna-forest boundary: how plant traits,

523 resources and fire govern the distribution of tropical biomes. Ecology Letters. 5:759-

524 768. https://doi.org/10.1111/j.1461-0248.2012.01789.x.

525

526 Katoh K, Misawa K, Kuma K and Miyata T (2002) MAFFT: a novel method for rapid multiple

527 sequence alignment based on fast Fourier transform. Nucleic Acids Research. 30:3059-66.

528 https://doi.org/10.1093/nar/gkf436

529

530 Kembel SW, Cowan PD, Helmus MR, Cornwell WK, Morlon H, Ackerly DD, Blomberg SP and

531 Webb CO (2010) Picante: R tools for integrating phylogenies and ecology. Bioinformatics.

532 26:1463-1464. https://doi.org/10.1093/bioinformatics/btq166 
534 Lanfear R, Frandsen PB, Wright AM, Senfeld T and Calcott B (2016) PartitionFinder2: New

535 methods for selecting partitioned models of evolution for molecular and morphological

536 phylogenetic analyses. Molecular Biology and Evolution. 34:772-773.

537 https://doi.org/10.1093/molbev/msw260

539 Leitner M, Davies AB, Parr CL, Eggleton P and Robertson MK (2018) Woody encroachment

540 slows decomposition and termite activity in an African savanna. Global Change Biology 24:

541 2597-2606. https://doi.org/10.1111/gcb.14118

542

543 Macfarlane C, Ryu Y, Ogden GN and Sonnentag O (2014) Digital canopy photography: exposed

544 and in the raw. Agricultural and Forest Meteorology. 197:244-253.

545 https://doi.org/10.1016/j.agrformet.2014.05.014

546

547 Maechler M, Rousseeuw P, Struyf A, Hubert M and Hornik K (2019) cluster: Cluster Analysis

548 Basics and Extensions. R package version 2.1.0.

550 Maravalhas J and Vasconcelos HL (2014) Revisiting the pyrodiversity-biodiversity hypothesis:

551 long-term fire regimes and the structure of ant communities in a Neotropical savanna hotspot.

552 Journal of Applied Ecology. 51: 1661-1668. https://doi.org/10.1111/1365-2664.12338

553

554 Martello F, de Bello F, Morini MSC, Silva RR, Souza-Campana DR, Ribeiro MC and Carmona

555 CP (2018) Homogenization and impoverishment of taxonomic and functional diversity of ants

556 in Eucalyptus plantations. Scientific reports 8:3266. https://doi.org/10.1038/s41598-018-20823-1 
558 Meira-Neto JA, Martins FR and Valente GE (2007) Composição florística e espectro biológico

559 na Estação Ecológica de Santa Bárbara, Estado de São Paulo, Brasil. Revista Árvore 31:907-

560 922. https://doi.org/10.1590/S0100-67622007000500015

562 Mouchet MA, Villéger S, Mason NWH and Mouillot D (2010) Functional diversity measures: an

563 overview of their redundancy and their ability to discriminate community assembly rules.

564 Functional Ecology. 24:867-876. https://doi.org/10.1111/j.1365-2435.2010.01695.x

566 Murphy BP, Andersen AN and Parr CL (2016) The underestimated biodiversity of tropical

567 grassy biomes. Philosophical Transactions of The Royal Society B. 371: 20150319.

568 https://doi.org/10.1098/rstb.2015.0319

569

570 Nguyen LT, Schmidt HA, Haeseler A and Minh BQ (2015) IQ-TREE: A fast and effective

571 stochastic algorithm for estimating maximum likelihood phylogenies. Molecular Biology and

572 Evolution. 32:268-274. https://doi.org/10.1093/molbev/msu300

573

574 Nobis M and Hunziker U (2005) Automatic thresholding for hemispherical canopy-photographs

575 based on edge detection. Agricultural and Forest Meteorology. 128:243-250.

576 https://doi.org/10.1016/j.agrformet.2004.10.002

577

578 Oksanen J, Blanchet FG, Friendly M, Kindt R, Legendre P, McGlinn D, Minchin PR, O’Hara

579 RB, Simpson GL, Solymos P, Henry M, Stevens H, Szoecs E and Wagner H (2020) vegan: 
580 Community Ecology Package. R package. Version 2.5-7.

582 Pacheco RPN and Vasconcelos HL (2012) Habitat diversity enhances ant diversity in a naturally

583 heterogeneous Brazilian landscape. Biodiversity and Conservation. 21:797-809.

584 https://doi.org/10.1007/s10531-011-0221-y

586 Paradis E and Schliep K (2018) ape 5.0: an environment for modern phylogenetics and

587 evolutionary analyses in R. Bioinformatics. 35: 526-528.

588 https://doi.org/10.1093/bioinformatics/bty633

590 Parr CL Dunn RR, Sanders NJ, Weiser MD, Photakis M, Bishop TR, Fitzpatrick MC, Arnan X, 591 Baccaro F, Brandão CRF, Chick L, Donoso DA, Fayle TM, Gómez C, Grossman B, Munyai TC, 592 Pacheco R, Retana J, Robinson A, Sagata K, Silva RR, Tista M, Vasconcelos HL, Yates M and 593 Gibb H. 2017. GlobalAnts: a new database on the geography of ant traits (Hymenoptera:

594 Formicidae). Insect Conservation and Diversity 10: 5-20. https://doi.org/10.1111/icad.12211

596 Parr CL, Gray E, and Bond WJ (2012) Cascading biodiversity and functional consequences of a 597 global change-induced biome switch. Diversity and Distributions. 18: 493-503.

598 https://doi.org/10.1111/j.1472-4642.2012.00882.x

600 Pavoine S, Ollier S and Pontier D (2005) Measuring diversity from dissimilarities with Rao's 601 quadratic entropy: are any dissimilarities suitable? Theoretical Population Biology. 67: 231-9. 602 https://doi.org/10.1016/j.tpb.2005.01.004 
604 Peck JE (2011) Fast, easy, and publication-quality ecological analyses with PC-ORD. The

605 Bulletin of the Ecological Society of America. 92: 298-301. https://doi.org/10.1890/0012-9623-

$606 \quad 92.3 .298$

607

608 R Core Team (2021). R: A language and environment for statistical computing. R Foundation for

609 Statistical Computing, Vienna, Austria. URL https:/www.R-project.org/.

610

611 Rao CR (1982) Diversity and dissimilarity coefficients: a unified approach. Theoretical

612 population biology. 21:24-43. https://doi.org/10.1016/0040-5809(82)90004-1

613

614 Revell LJ (2012) phytools: an R package for phylogenetic comparative biology (and other

615 things). Methods in Ecology and Evolution. 3: 217-223. https://doi.org/10.1111/j.2041-

$616 \quad 210 X .2011 .00169 . x$

617

618 Ribeiro R, Ricklefs RE, and Marinho J (2020) Partitioning beta diversity to unravel mechanisms

619 underlying the distributions of nonvolant small mammals in Brazil's Cerrado. Journal of

620 Mammalogy. 101:1438-1450. https://doi.org/10.1093/jmammal/gyaa085

621

622 Rocha-Ortega M, Arnan X, Ribeiro-Neto JD, Leal IR, Favila ME and Martínez-Ramos M (2018)

623 Taxonomic and functional ant diversity along a secondary successional gradient in a tropical

624 forest. Biotropica. 50: 290-301. https://doi.org/10.1111/btp.12511 
626 Rosan TM, Aragão LEOC, Oliveras I, Phillips OL, Malhi Y, Gloor E. and Wagner FH (2019)

627 Extensive 21st-Century woody encroachment in South America's savanna. Geophysical

628 Research Letters. 46:6594-6603. https://doi.org/10.1029/2019GL082327

629

630 Santoandré S, Filloy J, Zurita GA and Bellocq MI (2019) Ant taxonomic and functional diversity

631 show differential response to plantation age in two contrasting biomes. Forest Ecology and

632 Management. 437:304-313. https://doi.org/10.1016/j.foreco.2019.01.021

633

634 Schleppi P, Conedera M, Sediyy I and Thimonier A (2007) Correctiong non-linearity and slope

635 effects in the estimation of the leaf area index of forests from hemispherical photographs.

636 Agricultural and Forest Meteorology. 144:236-242.

637 https://doi.org/10.1016/j.agrformet.2007.02.004

638

639 Silvestre M, Carmona CP, Azcárate FM and Seoane J (2021) Diverging facets of grassland ant

640 diversity along a Mediterranean elevational gradient. Ecological Entomology.

641 https://doi.org/10.1111/een.13077

642

643 Simon MF and Pennington T (2012) Evidence for fire adaptation to fire regimes in the tropical 644 savannas of the Brazilian Cerrado. International Journal of Plant Sciences. 173:711-723.

645 https://doi.org/10.1086/665973

646

647 Smithsonian Institution. 2021. High Performance Computing Cluster.

648 https://doi.org/10.25572/SIHPC 
650 Stevens N, Lehmann CER, Murphy BP and Durigan G (2017) Savanna woody encroachment is

651 widespread across three continents. Global Change Biology. 23:235-244.

652 https://doi.org/10.1111/gcb.13409

653

654 Strassburg B, Brooks T, Feltran-Barbieri R, Iribarrem A, Crouzeilles R, Loyola R, Latawiec AE, 655 Oliveira-Filho FJB, Scaramuzza CAM, Scarano FR, Soares-Filho B and Balmford A (2017)

656 Moment of truth for the Cerrado hotspot. Nature Ecology and Evolution. 1:0099.

657 https://doi.org/10.1038/s41559-017-0099

658

659 Swenson NG and Weiser, MD (2014) On the packing and filling of functional space in eastern

660 North American tree assemblages. Ecography. 37:1056-1062.

661 https://doi.org/10.1111/ecog.00763

662

663 Tagliacollo VA and Lanfear R (2018) Estimating improved partitioning schemes for

664 Ultraconserved Elements. Molecular Biology and Evolution. 35:1798-1811.

665 https://doi.org/10.1093/molbev/msy069

666

667 Thimonier A, Sedivy I and Schleppi P (2010) Estimating leaf area index in different types of

668 mature forest stands in Switzerland: a comparison of methods. European Journal of Forest

669 Research. 129:543-562. https://doi.org/10.1007/s10342-009-0353-8

670

671 Webb CO (2000) Exploring the phylogenetic structure of ecological communities : an example 
672 for rain forest trees. American Naturalist.156:145-155. https://doi.org/10.1086/303378

673

674 Webb CO, Ackerly DD, McPeek MA and Donoghue MJ (2002) Phylogenies and community

675 ecology. Annual Review of Ecology and Systematics. 33:475-505.

676 https://doi.org/10.1146/annurev.ecolsys.33.010802.150448

677

678 Weiser MD and Kaspari M (2006) Ecological morphospace of New Worlds ants. Ecological

679 Entomology. 31:131-142. https://doi.org/10.1111/j.0307-6946.2006.00759.x

680

681 Woinarski J, Risler L and Kean JCZ (2008) Response of vegetation and vertebrate fauna to 23

682 years of fire exclusion in a tropical Eucalyptus open forest, Northern Territory, Australia. Austral

683 Ecology. 29:156-176. https://doi.org/10.1111/j.1442-9993.2004.01333.x

684

685 Wood SN (2017) Generalized Additive Models: An Introduction with R, Second Edition (2nd 686 ed.). Chapman and Hall/CRC. 


\section{$687 \quad$ Figure legends}

688 Figure 1. The relationship between tree cover (Leaf Area Index, LAI) and ant alpha diversity. (a)

689 Taxonomic diversity, (b) observed functional diversity, (c) standardized effect size of functional

690 diversity, (e) observed phylogenetic diversity, (f) standardized effect size of phylogenetic

691 diversity. (d) Differences in LAI between plots classified as open savanna, dense savanna or

692 forest at the time of the ant sampling.

693

694 Figure 2. Results of the variation partitioning analysis showing the amount of variation in the 695 taxonomic, functional or phylogenetic dissimilarity of ant communities explained uniquely by

696 differences in tree cover (LAI), by the spatial distance between sampling plots, or by these two

697 factors combined.

698

699 Figure 3. nMDS ordination plot of the ant communities in relation to their (a) taxonomic, $(\mathrm{b}, \mathrm{c})$

700 functional, or (d, e) phylogenetic dissimilarities (beta diversity). The symbol size is proportional

701 to the Leaf Area Index (LAI) of the sampling plot. 
Figure 1
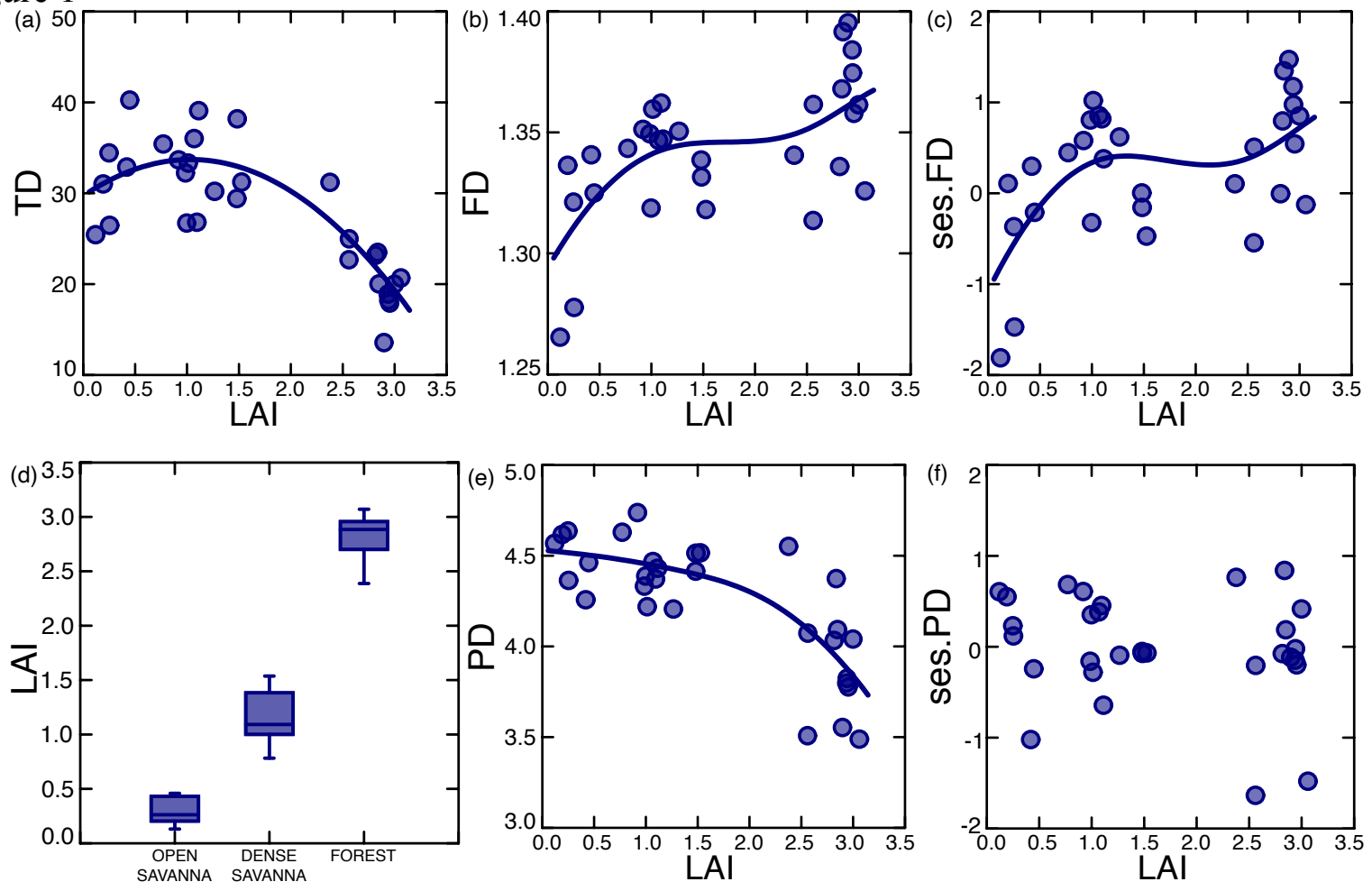
Figure 2

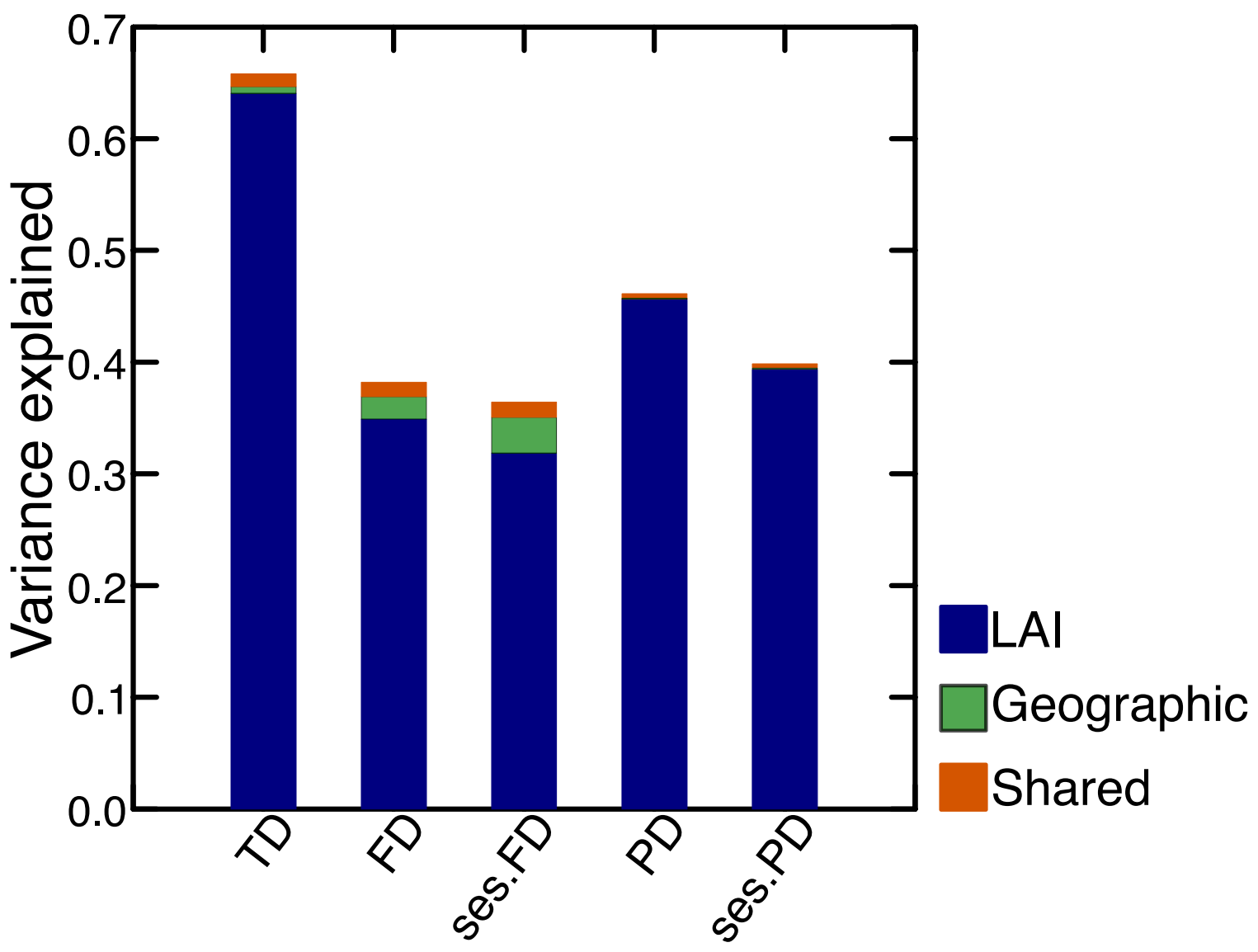


Figure 3
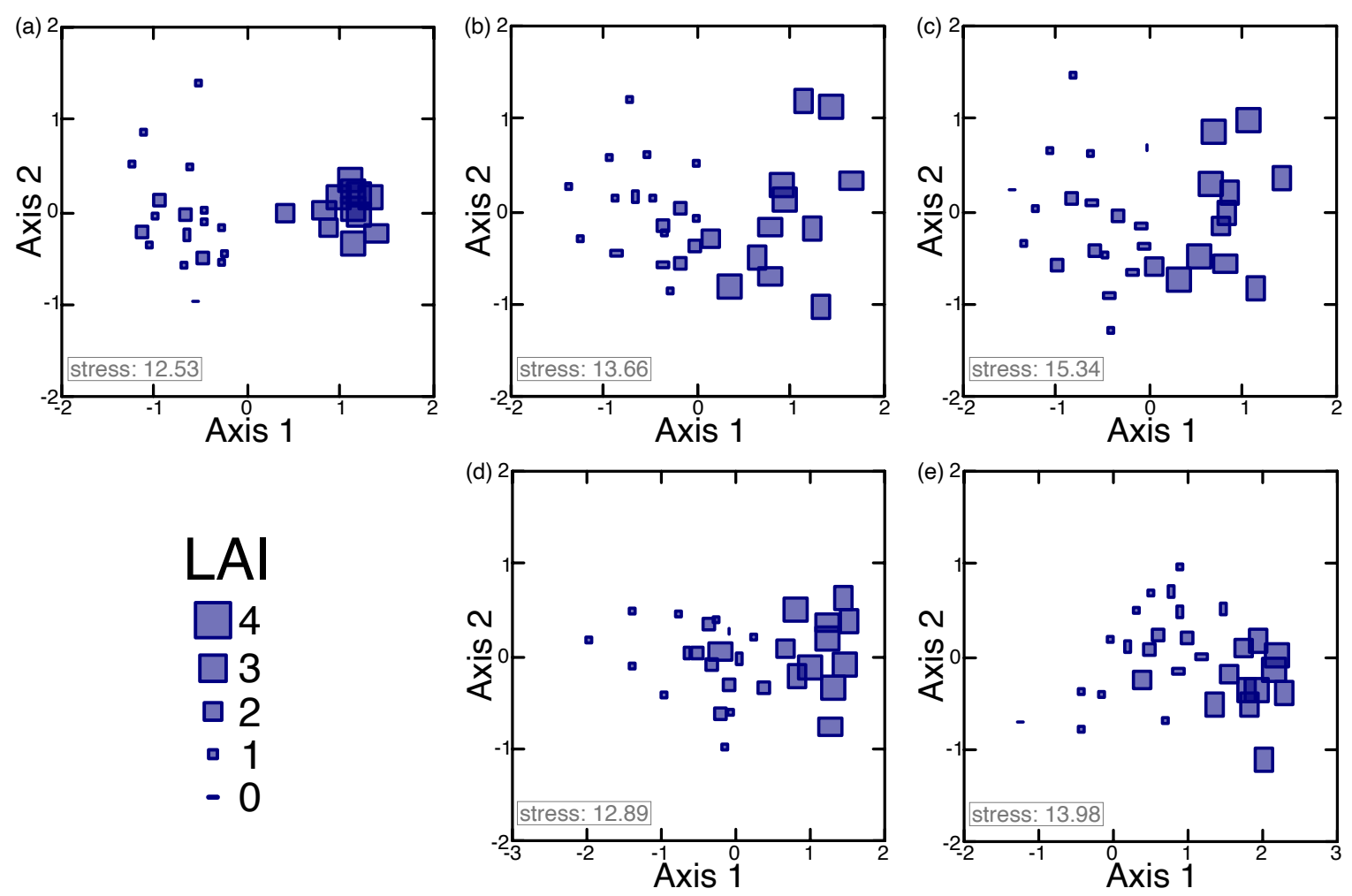


\section{Supplementary Files}

This is a list of supplementary files associated with this preprint. Click to download.

- OnlineResource1TreeCoverAntdiversity.pdf

- OnlineResource2TreeCoverAntdiversity.pdf 